\title{
Study on Teaching Method Reform and Model Research of Practice Course in Agricultural Colleges
}

\author{
Yueling Zhao ${ }^{1, a^{*}}$, Haiyan Han ${ }^{2, c}$, Liying $\mathrm{Cao}^{1, \mathrm{~b}}$ and Guifen Chen ${ }^{1, \mathrm{~d}}$ \\ ${ }^{1}$ Jilin Agricultural University, Changchun, 130118, China; \\ ${ }^{2}$ Changchun Universities, Changchun, 130000, China \\ azyueling@163.com, b275714495@ qq.com, c453876175@qq.com,,1045093555@qq.com
}

Keywords: Agricultural colleges; Curriculum setting; Teaching practice; Teaching reform

\begin{abstract}
Colleges and universities is to cultivate the base of high-tech talent, only by constantly exploration, innovation, to develop suitable for the present situation of today's high-tech creative talents. Based on energy conservation and emissions reduction problems exist in the practice teaching, put forward the practice of energy conservation and emissions reduction course curriculum reform specific measures and methods. Practice has proved that the practice teaching system is complete, has certain operability, cultivate the students by this way, its professional level and technical quality and employment competitiveness are improved.
\end{abstract}

\section{Introduction}

At present, the humanity is facing the world's energy shortage and serious destruction of ecological environment. They are the dual challenge during the twelfth five-years. It was compared from 2010 to 2015 , per unit of GDP energy consumption reduced by $16 \%$, chemical oxygen demand and sulfur dioxide emissions decreased by $8 \%, 17 \%$ less carbon dioxide emissions and other hard target. Our country from to achieve the eighteenth big dream beautiful China one of the important path and form, low carbon travel, saving energy is the development of the society order, it is also the root causes of the energy conservation and emissions reduction. If technology to implement the effective energy saving and emission reduction, the purpose of the "beautiful China" are getting closer and closer to us ${ }^{[1]}$. Increase the implementation of energy-saving emission reduction policies in China is imminent, how to speed up the realization of energy conservation and emissions reduction targets, make our country a resource-conserving, environment-friendly society, it is also a task in the institutions of higher learning in the process of talent training.

As high-tech talent cultivation in colleges and universities, we must be under the leadership of the party and the government, continuous exploration, innovation, actively explore a suitable for the current situation of agricultural colleges practical teaching methods, to cultivate a new generation of college students come up with new ideas, high quality, to make due contributions.

\section{Performance Problems}

Interaction between University and Enterprise. University-enterprise cooperation in running schools is one of the development and direction of the reform of institutions of higher learning, although a lot of colleges and universities are actively study and explore the mode and method of university-enterprise cooperation in running schools, but also exist some problems in practical operation, due to the reason mainly lies in the fact that enterprises participate in the initiative is not enough to it, did not reach their maximum profit goals. University-enterprise cooperation "guerilla" exist problems of supply and demand, market prospect is good, will increase demand for talent, on the contrary is shrinking talent demand, the economic interests of the enterprise makes the influence of university-enterprise cooperation potential and prospect of the other to a certain extent people worry ${ }^{[2]}$.

Problems of Local Government. Although the central government attaches great importance to energy conservation and emissions reduction, and vigorously promote and implement, but the 
implementation of energy conservation and emissions reduction work mainly by the provincial, city and county and key enterprises, in order to guarantee the rapid development of economy in this area, some local governments still widely in energy conservation and emissions reduction work not as a phenomenon, they are only one-sided pursuit of economic growth index, do not take the index system of energy conservation and emissions reduction, will make a lot of angels exist hero serves no purpose of energy saving and emission reduction, this virtually also foiled some perform all confidence and hope, eventually led to the enterprise about comprehensive utilization of energy tax breaks, subsidies and other measures is difficult to implement.

Application of Teaching and Learning. Institutions of higher learning mastery of enterprise talent demand is insufficient, in the process of practice teaching, of inadequate investment funds, and a major cause of the effect is not often ideal ${ }^{[3]}$. There are not adapt phenomenon that students have encountered in the process of talent cultivation in colleges and universities, and their teaching practice with the enterprise's current positions demand. So to some extent it must be meet the demand of the enterprise. And although I am in the process of higher education, has been focused on undergraduate talent training application ability and innovation ability, but in some ways there are likely to be relatively surplus phenomenon.

In the process of practice teaching, the teacher taught the theory of knowledge is too detailed, practical applications since there is no space, the lack of tools or the actual enterprise existence state of distrust, to perfect the practice teaching has certain resistance.

In order to speed up the relevant teaching content reform in colleges and universities, and out of school, only to strengthen the enterprise energy saving institutions, government and colleges and universities cooperate, can make the national consciousness of energy conservation and technology level to further improve, energy-saving emission reduction technology steadily push forward for the application to the practice of production, make a due contribution to the sustainable development of environment.

\section{Reform Specific Measures}

To Understand the Concept of Education. Some local government officials have awareness of energy conservation and emissions reduction level is not high, their policy for energy conservation and emissions reduction "mouth Shouting slogans, actual do another set of". Some local governments to the one-sided pursuit of achievements, dry face, image engineering. This requires our continuous efforts and participation of the modern college students, change the backward situation.

Actively carry out low carbon education, let the students learning under the low carbon environment and education mode, more directly and effectively improve their environmental protection, energy conservation and emissions reduction, in the face of the earth's climate warming, understanding and the understanding of the construction of ecological civilization, gradually formed itself and the surrounding people low carbon behavior and way of life, so teachers in teaching process, from the aspects of social and economic interests from many angles to help students to understand the meaning and importance of energy saving, so as to help students build up the consciousness of energy conservation and social responsibility ${ }^{[4]}$.

To Improve the Teaching Method. A professional teaching plan, is the foundation of the whole teaching, is the basis of each teaching link. With the development of social economy, puts forward new requirements to the talent training, should adjust the teaching plan, make the talents training and social and economic development.

In the process of practice teaching, driven by task type teaching, strengthening students' autonomous learning enthusiasm and initiative, team discussion-based teaching research method. Teachers according to the teaching goal of course on each task decomposition and synthesis, according to the requirements of task, the students should understand and grasp the knowledge of permeability and reinforcement, the process, teachers should pay attention to in the process of set tasks, attention should be paid to the following aspects: a quantity to reach a certain level to ensure that the mission; Second, we must fully consider the knowledge needed to complete the task of 
comprehensive; Third, we need to put the task design best with practical applications and facilitate promotion as the main body; Fourth, we need to make the end of the task to complete the inspection standard and unified. With it's corresponding to the energy conservation and emissions reduction course practice teaching mode, as shown in the figure1.

The cultivation of students' innovative ability is to some extent with the effective scientific research thinking and innovation consciousness inseparable. Accordance with the plans to open experiment teaching process, teachers should have a serious influence on ecological environment of the oxidation of carbon, sculpture dioxide and other waste gas produced in the process and mechanism on the basis of the key research. In the actual teaching, the general trend of the development of this discipline, actively carry out practice teaching research, to strengthen the construction of practice teaching of this subject research. In order to improve the students' interest in learning, to make it more active to study and research of this professional knowledge, hope the teacher in teaching process, it is base point with between the team teaching, with some heuristic and discussion-based teaching mode. Teachers can also use their spare time and students together to research and development of practice teaching in agricultural colleges teaching courseware, to make the students in middle school, learning research, promote and improve each other.

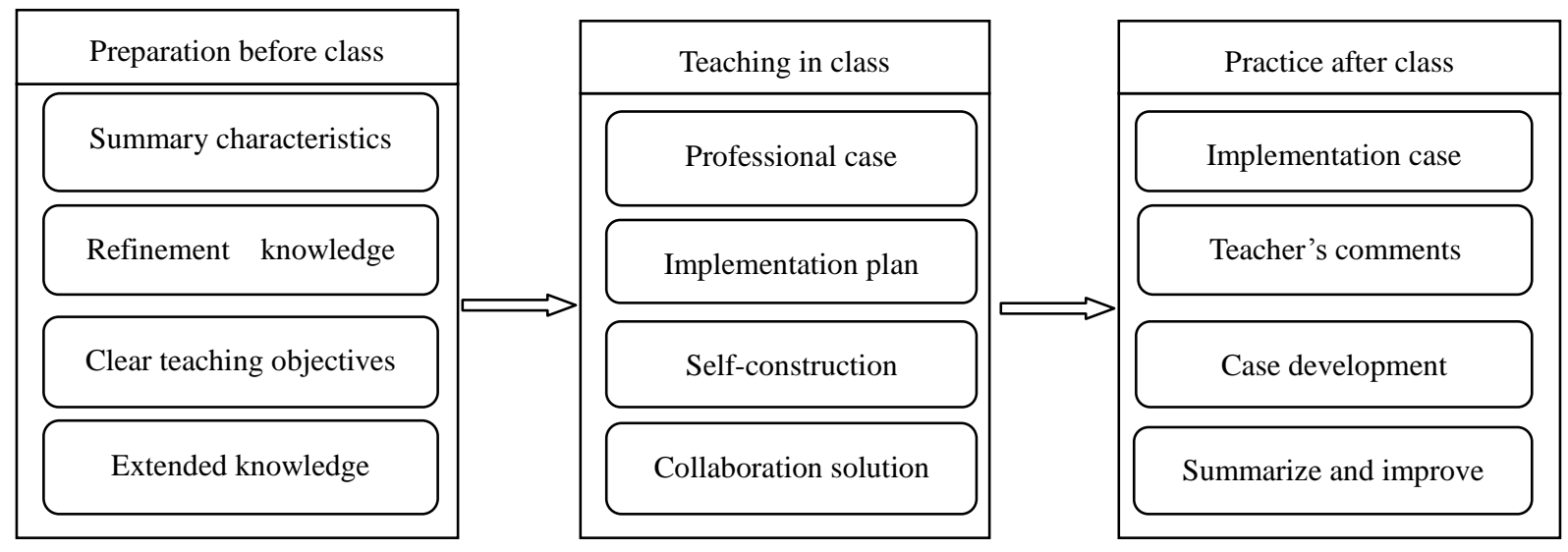

Figure 1. Practice teaching pattern of agricultural colleges

The Strengthen Practice Teaching. So-called practice teaching is more than college students to use their eyes to observe, to experience through practice, through the brain to think and create, is a knowledge, feeling, meaning, the unity of education process, it is to improve college students comprehensive quality and the effective ways to cultivate college students' talents.

Experiment teaching can strengthen the social responsibility of college students, make contemporary college students through teaching practice, witnessed in the current society, the enterprise production actual situation, can further clarify their shoulder the historic mission, this aspect in order to enhance its social responsibility, on the other hand can motivate students in accordance with the requirements of social development to continuously develop and improve themselves.

In the practice teaching, every college students is an active participant, not a passive listener. In the social service oriented practice in the process of teaching activities, the college students' use of individual talents and services to the society both organically, the realization of individual value and dedication social integration, and this is precisely one of the surest way to college students' comprehensive quality to improve. Therefore, effective practice teaching method can improve the students' cultural quality, profession. It is also effective platform and means of college students' comprehensive quality improving.

To Strengthen the Laboratory Opening. Experiment center according to the actual situation of the laboratory, to formulate the corresponding system of laboratory opening. Is a basic laboratory management measures and the student code of conduct. The second is to strengthen the students' autonomous consciousness. Three open ready to experiment to the students' investigation and level of the performance test. Four system to increase the number of undergraduate science and 
technology innovation laboratory opening, at the same time to formulate the corresponding incentive measures, for teachers and students to provide an efficient, rapid scientific and technological innovation platform.

To Established of External Base. Practical teaching in agricultural universities, should set up outside the research and development base, it is the beneficial supplement of the practice teaching courses, by establishing practice base outside school students on the one hand, can for the connection of theoretical knowledge and practical production, on the other hand can be applied supplemental students' knowledge of the industry. Get students to the deep understanding of the energy conservation and emissions reduction.

As a result, the practice of the agricultural colleges teaching plan constant revision and improvement, adhere to the indoor experiment and practice of combining the outdoor road, to help students learn knowledge, use knowledge for the principle, to create conducive to the development of college students' personality and common good experiment and practice environment, improve the professional talents of innovative, to improve the training quality. To this end, our school has established nearly 20 off-campus practice base. Achieve mutual benefit and common development cooperation targets, finally realizes the schools, enterprises and the overall goals of students and social profit.

\section{Conclusion}

We work through the study above trial practice teaching mode, build the practical teaching system with local characteristics of the subject. After nearly four years of professional energy saving and emission reduction in our school students cultivate practice as a result, it can be seen in this way to cultivate the students comprehensive quality and practice ability training of all present a rapid growth, its level of professional and technical quality and the employment competitive power is improved. The practice course teaching has proved that has been completed and has certain operability.

\section{Acknowledgements}

Funds for the research was provided by scientific research fund of Jilin Agricultural University (No.201620) ,Jilin province university undergraduate science and technology innovation fund. National university undergraduate science and technology innovation fund (No.201510193040).spark plan Ministry of science and technology (2015GA660004).

\section{References}

[1] ZhengXiaohuan. Local government to promote energy conservation and emissions reduction countermeasures research [D]. 2014 tianjin university of commerce. (In Chinese).

[2] Ya-bin xu. Research and practice of University-enterprise cooperation personnel training mode [J]. Computer education .2013 (2): 1-4. (In Chinese).

[3] Yun-linzhao. Local undergraduate course of teaching reform breakthrough [J]. Practice teaching: 2008 (12): 51-52. (In Chinese).

[4] Zhi-guo sun, Hai-ping xu. The teaching reform discussion situation of energy saving and emission reduction in environmental systems [J]. Journal of education teaching exploration (9): 2012-60. (In Chinese). 